\title{
Remote Control of Room Lights and Coolers Automation System SMS Based
}

\author{
Kadek Dwi Wahyuadnyana*, Anak Agung Ngurah Gunawan, Ida Bagus Alit Paramarta \\ Physics Department of Mathematics Faculty and Natural Sciences of Udayana University, Bali, Indonesia
}

Corresponding Author Email: a.a.n.gunawan.unud@gmail.com

https://doi.org/10.18280/jesa.520413

Received: 10 April 2019

Accepted: 15 July 2019

\section{Keywords:}

LM35 sensors, passive infrared receiver (PIR) sensors, automation system, remote control, light intensity

\begin{abstract}
This paper attempts to design a system based on the sensors on the market, enabling intelligent automatic control the electronic devices in our homes. For this purpose, the authors created an automation system for room lights and coolers that can be remotely controlled. The system detects human movements with passive infrared receiver (PIR) sensors, measures the room temperature by LM35 sensors, and captures the light intensity of the room by light dependent resistor (LDR) sensors. The data of the three sensors are processed using ATMega2569 microcontroller. The key components of the system were programmed in $\mathrm{C}$ language. The measured results of the proposed system were compared with those of standard tools. The comparison shows no significant difference between the two sets of results, with a confidence level of $95 \%$. Therefore, our system is of great help to those who often forget to turn off electronic devices in their rooms.
\end{abstract}

\section{INTRODUCTION}

Indonesia is included in the list of 23 countries with the highest energy consumption in the world. The list was issued by a non - profit organization from the United States (US), American Council for Energy - Efficient Economy (ACEEE). Based on ACEEE report, Indonesia ranks $17^{\text {th }}$ in 23 groups of countries related to the level of energy efficiency [1]. This is also supported by the increase in per capita electricity of consumption from 2014 to 2017.

In 2014 Indonesia's electricity consumption per capita was $812 \mathrm{Kwh}$ so that in 2017 Indonesia's electricity consumption per capita increased to $1000 \mathrm{Kwh}$ [2], and of course this increase will occur continuously every year. Increased consumption of electrical energy is due to the increase in living standards that occur in Indonesia which has resulted in an increase in the number of equipment that requires electrical energy. In addition, increased consumption of electrical energy is certainly influenced by human error, for example is forgetting to turn off electrical equipment when leaving a room or house.

Based on the issues, the authors have made an automation system for lighting and air conditioning that only works if human activity is detected in the room. Therefore, there will be no waste of electrical energy. And, this system can be controlled remotely by SMS. If with the assumption that humans leave home \pm 18 hours per day, it can be said the system will help prevent electricity uses by $\pm 75 \%$. Then it can be said that human influence on energy savings is $\pm 75 \%$ and the rest depends on the quality of the technology and equipment used. This indicates that, humans have a large role in energy saving activities.

Automation is defined as a technology that is concerned with the use of mechanical, electronic, and computer - based systems in the operation and control of production [3]. Therefore, we need an automation system design that is able to control electrical equipment such as lights and coolers to save electrical energy SMS based. The tool used to receive and send SMS as a remote control is the SIM800L GSM Module. A relay is an electromagnetic switch which is used to switch High Voltage/Current using Low power circuits [4]. The main usage of the relay was seen in the history for transmitting and receiving the information, that was called as Morse code where the input signals used to be either 1 or 0 [5]. The system will automatically turn on lights and coolers with relay if detected human activity in the room by considering the condition of the room (light intensity and room temperature), and will turn off the lights and coolers if no human activity is detected in the room. This system is able to send information about ON/OFF the lights and coolers to the owner's room cellphone via SMS. This is intended if an error occurs in the system, then the owner's room is able to control the system via his cellphone from far away. Thus, this system will not allow lights and coolers to turn on continuously if the room is not being used by humans.

The remainder of this paper is organized as follows: Section 2 introduces the research methodology, such as the designed tools, how to do the research, what tools and materials are needed to conduct the research, and how to process the data. Section 3 shows the results of research that has been done, and discuss it in Section 4. Like mistakes that were not intentionally made when making design tools and when doing research. And the last section, Section 5, contains conclusions about the whole experiment and provides some suggestions and tips for future researchers who conducting the similar studies.

\section{RESEARCH METHODS}

\subsection{Research designs}

This research is an experimental type by designing remote control lights and coolers automation systems using 
ATMega2560 microcontroller with SMS based. The purpose of this research is to assist in the activities of saving electrical energy and to know the difference results of measurements between the designed tools and standard equipment. One of the most important parts of the project is programming process which can be done by $\mathrm{C}$ language [6]. The flow chart and block diagram of the designed tools can be seen in Figure 1 and Figure 2.

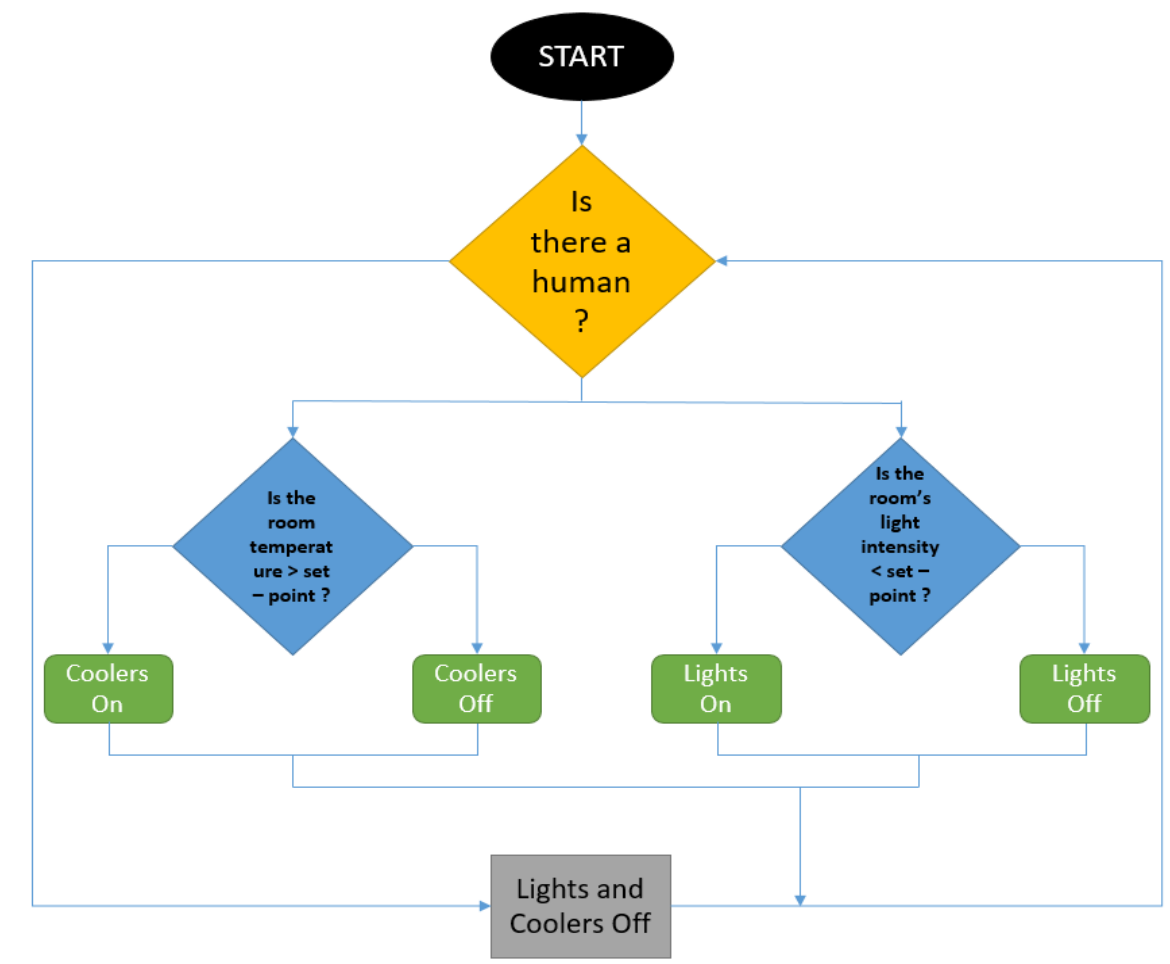

Figure 1. Designed tools in flow chart

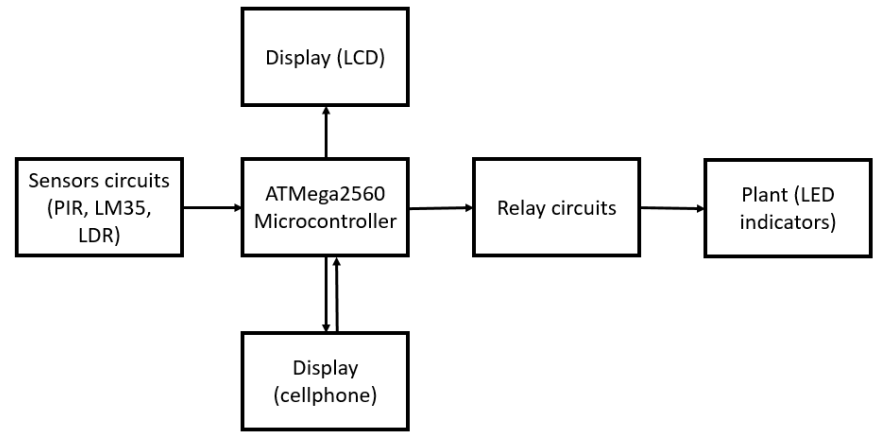

Figure 2. Designed tools in block diagram

\subsection{Measurement and observation parameters}

Measurements are carried out in four different room conditions (Dark - Cold, Dark - Hot, Bright - Cold, and Bright - Hot). From each of these conditions, measurements were taken as much 35 times for each sensor (PIR, LM35, and LDR).

The results of the measurement of temperature and light intensity of each room conditions are then compared with standard tools.

\subsection{Research instruments}

The sensor used is Passive Infrared Receiver (PIR) to detect human movement [7], then the LM35 sensor to measure the room temperature, and the Light Dependent Resistor (LDR) sensor to measure the light intensity of the room. Then, these three sensors are processed using
ATMega2569 microcontroller. The microcontroller consists of CPU, RAM, ROM, and input/output ports embedded in a small chip [8]. Unlike a microprocessor, it includes processor with memory location for storing programs written in $\mathrm{C}$ language [9]. The maximum voltage is 24volt, and is limited up to $5 \mathrm{~V}_{\text {ref }}$ Pulse Width Modulation Signal [10]. This research was started at the author's residence from December 8, 2018 to February 8, 2019.

\subsection{Data collection and analysis procedures}

In order for the automation system works properly, a set point is needed. The set point used in this research is $25^{\circ} \mathrm{C}$ for the LM35 temperature sensor (if the room temperature is below $25^{\circ} \mathrm{C}$ the system will turn off the coolers because the room is already cold, and vice versa, if the room temperature is above $25^{\circ} \mathrm{C}$ the system will turn on the coolers because the room is already hot). The next set point is 300lux for the LDR light intensity sensor (if the light intensity of the room is below 300lux the system will turn on the lights because the room is already dark, and vice versa, if the light intensity of the room is above 300lux the system will turn off the lights because the room is already bright).

Measurements of temperature and light intensity is carried out at each conditions of the room at the same time. Measurements are carried out by changing the amount of temperature and intensity of light in the room varies. This aims to improve the data variant.

To test the difference measurements between the designed tools and the standard tools, the average difference test is used manually by calculating $\mathrm{Z}_{\mathrm{cal}}$ and using IBM SPSS Statistics 22 application to make sure that the measurement 
results are tested properly. If the value of $\mathrm{Z}_{\mathrm{cal}}<\mathrm{Z}_{\text {table }}[10]$ and $\mathrm{p}$ - value shown by the results of IBM SPSS Statistics 22 is greater than 0.05 , it means there is no significant difference between the average results of measurements of the designed tools and the standard tools.

\section{RESEARCH RESULTS}

The results obtained from this research are lights and coolers automation system that can be controlled remotely by owner's room cellphone with SMS based. The results of the designed tools can be seen in Figure 3. This system used the GSM SIM 800L module as a medium of communication between systems with the owner's room cellphone as shown in Figure 4. GSM SIM 800L is designed to interface with the $5 \mathrm{~V}$ DC TTL and $3 \mathrm{~V} 3$, this allows users to easily interface with 5V MCUs (PIC, AVR, Arduino, 8051, etc.) [12]. All measured data from each sensor and its algorithm in the execution of the plant (lights and coolers) and sending SMS to the owner's room (as a remote controller) are processed by the ATMega2560 microcontroller. This system consists of two main circuits namely: Remote control circuit and automation system circuit.

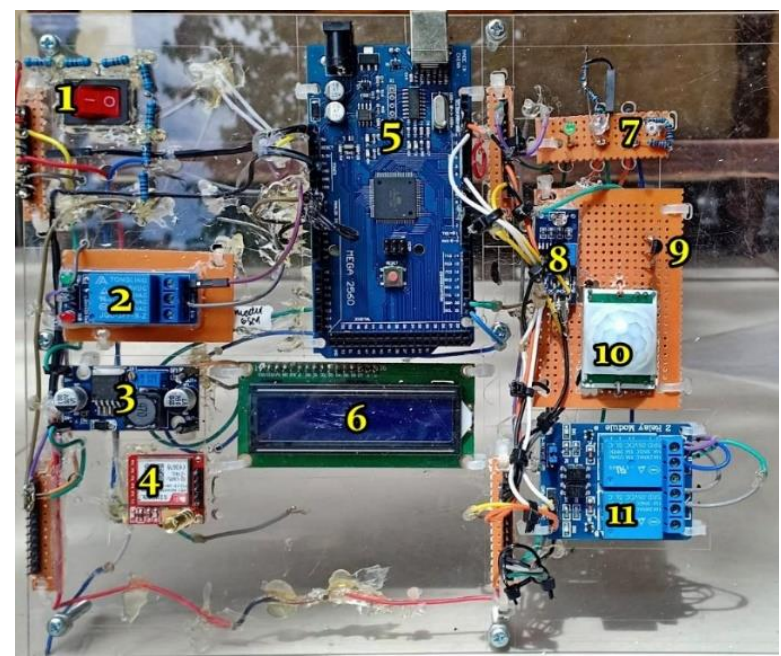

Figure 3. Designed tools looks like

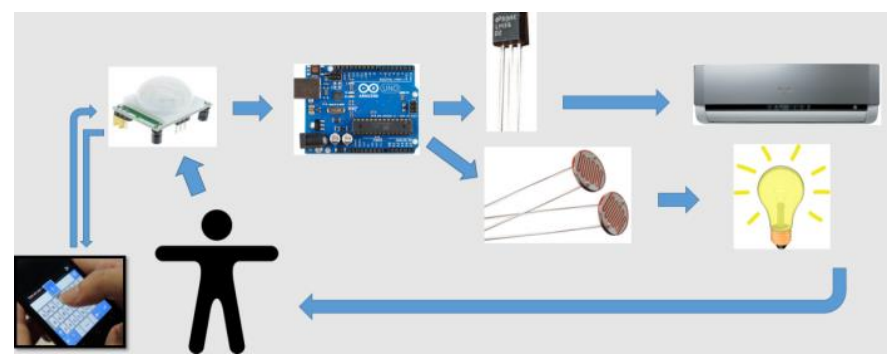

Figure 4. System work flow in general

From the measurement results it was found that the PIR sensor was able to work well at a distance of $0-5$ meters with an angle $(\theta) 0^{\circ}<\theta<180^{\circ}$ to the sensor.

In Dark - Cold conditions the results of the linear regression coefficient between the designed tools and standard tools are $98.67 \%$ for LDR sensors and $95.25 \%$ for temperature sensors. The results of statistical tests obtained by $\mathrm{Z}_{\mathrm{cal}}$ were -1.01 ( $\mathrm{p}$ - Value of 0.126 ) for LDR sensors and $\mathrm{Z}_{\mathrm{cal}}$ were -2.71 ( $\mathrm{p}$ - Value of 0.126) for temperature sensors.

In Dark - Hot conditions the results of the linear regression coefficient between the designed tools and standard tools are $91.94 \%$ for LDR sensors and $92.32 \%$ for temperature sensors. The results of statistical tests obtained by $\mathrm{Z}_{\mathrm{cal}}$ were -9.00 ( $\mathrm{p}$ - Value of 0.245 ) for LDR sensors and $\mathrm{Z}_{\mathrm{cal}}$ were -7.90 ( $\mathrm{p}$ - Value of 0.054) for temperature sensors.

In Bright - Cold conditions the results of the linear regression coefficient between the designed tools and standard tools are $97.18 \%$ for LDR sensors and $95.19 \%$ for temperature sensors. The results of statistical tests obtained by $\mathrm{Z}_{\text {cal }}$ were -0.05 ( $\mathrm{p}$ - Value of 0.462 ) for LDR sensors and $\mathrm{Z}_{\mathrm{cal}}$ were -2.60 ( $\mathrm{p}$ - Value of 0.060) for temperature sensors.

In Bright - Hot conditions the results of the linear regression coefficient between the designed tools and standard tools are $92.02 \%$ for LDR sensors and $93.8 \%$ for temperature sensors. The results of statistical tests obtained by $\mathrm{Z}_{\text {cal }}$ were -0.02 ( $\mathrm{p}$ - Value of 0.702 ) for LDR sensors and $\mathrm{Z}_{\mathrm{cal}}$ were -1.67 ( $\mathrm{p}$ - Value of 0.220 ) for temperature sensors. All statistical test results obtained using a level of confidence $(\alpha)=95 \%$.

\section{DISCUSSIONS}

The linear regression coefficient is a quantity that represents the suitability of the measurement results between the designed tools and standard tools, the greater the linear regression coefficient $(100 \%)$, the more appropriate the standard tools.

From the experiments carried out it was found that there was a change in the linear regression coefficient of each room's conditions.

From the Dark - Cold to the Dark - Hot room's conditions there is a difference in the linear regression coefficient of $6.73 \%(98.67 \%-91.94 \%)$ for the LDR sensor and $2.93 \%$ $(95.25 \%-92.32 \%)$ for temperature sensors. Likewise, the Bright - Cold to the Bright - Hot room's conditions has a difference in the linear regression coefficient of $5.16 \%$ for the LDR sensors and $1.39 \%$ for the temperature sensor. It can be seen that the biggest difference is indicated by the measurement results by the LDR sensors. This is caused by several factors: temperature changes detected by the LM35 temperature sensors can cause the regulation of the distribution of electrical power to all components disturbed, so that it affects the electrical power supply to the LDR sensor to read the light intensity. The next factor is due to lack of quality in making designed tools so that designed tools are very sensitive to small collisions.

The designed tools that has been made by the author is now equipped with a remote controller using SMS. If the room's owner wants to turn off this designed tool from away even far away - while getting GPRS signal [13] only by sending an SMS command "OFF" then the designed tools becomes inactive and sends the SMS confirmation again that the tools is completely off. Likewise, if the room's owner wants to turn on the designed tools only by sending an SMS with the command "ON", then the designed tools returns active. The cellphone is set to understand the message been sent to it. So, after the message have been send to cell phone it senses weather the code is from the desired number and whether the code is correct [14]. 


\section{CONCLUSIONS AND RECOMMENDATIONS}

From the research carried out it has been successfully designed to build an automation system that can be controlled remotely based on SMS. The results of the measurement of light intensity and room temperature between the designed tools and standard tools have a precision level of $98.67 \%$ and $95.25 \%$ for the Dark - Cold rooms, $91.94 \%$ and $92.32 \%$ for the Dark - Hot rooms, $97.18 \%$ and $95.19 \%$ for Bright - Cold rooms, $92.02 \%$ and $93.8 \%$ for Bright - Hot rooms.

From the results of statistical calculations by manual and using the IBM SPSS Statistics 22 application, there is no significant difference in the average measurement results between the designed tools and standard tools with a confidence level of $95 \%$.

For the next researcher it is recommended to use a GSM module that is capable of receiving HSDPA signals or better known as $3 \mathrm{G}$ because the $3 \mathrm{G}$ network expansion is also a large investment for operators [15] has spread evenly throughout the region rather than the GPRS network.

\section{REFERENCES}

[1] The International Energy Efficiency Scorecard. https://aceee.org/portal/national-policy/internationalscorecard, accessed on Jan. 3, 2019.

[2] Indonesia - Electric power consumption (kWh per capita).

https://tradingeconomics.com/indonesia/electric-powerconsumption-kwh-per-capita-wb-data.html, accessed on Jan. 3, 2019.

[3] Manjula, V.S., Karamagi, RI. (2018). Automatic pick and place robot manipulation using a microcontroller. Journal of Applied \& Computational Mathematics, 7(3): 1. https://doi.org/10.4172/2168-9679.1000408

[4] Bamisaye, J., Ayodeji, B., Ademiloye, I. (2016). Microcontrollers based smart control system with computer interface. Journal of Electrical \& Electronic Systems, 5(3): 2-3. https://doi.org/10.4172/23320796.1000186

[5] Relay: Construction, Working and Types, https://circuitdigest.com/article/relay-working-types- operation-applications, accessed on Feb. 18, 2019.

[6] Ardavan, M. (2016). Implementation of PID controller by microcontroller of PIC (18 Series) and controlling the height of liquid in sources. Advances in Robotics \& Automation, 5(3): 3. https://doi.org/10.4172/21689695.1000156

[7] Vikrant, V., Maulin, P., Saeed, Bagheri. (2017). A datadriven approach for accurate estimation and visualization of energy savings from advanced lighting controls. Innovative Energy \& Research, 6(2): 1. https://doi.org/10.4172/2576-1463.1000177

[8] Shirzadfar, H., Khanahmadi, M. (2018). Design and development of ECG simulator and microcontroller based displayer. Journal of Biosensors \& Bioelectronics, 9(3): 4-5. https://doi.org/10.4172/2155-6210.1000256

[9] Akinwole, O.O. (2018). Design and simulation of a 1 $\mathrm{kVA}$ arduino microcontroller based modified sine wave inverter using proteus. Journal of Electrical \& Electronics $\quad$ Systems, $\quad 7(4)$ : 1. https://doi.org/10.4172/2332-0796.1000282

[10] Ardiansyah, R.A., Yazid, E. (2017). Rotational speed control of brushless DC motor using genetic algorithm optimized PD controller. Jurnal Elektronika dan Telekomunikasi, $18(2)$ : 3. https://doi.org/10.14203/jet.v18.75-80

[11] Comparison of Two Means. http://www.stat.yale.edu/Courses/199798/101/meancomp.htm, accessed on Jan. 4, 2019.

[12] Jahlool, J.S. (2018). Automatic detection and correction the fault in electrical power feeders based microcontroller. Journal of Electrical \& Electronic Systems, 7(3): 2. https://doi.org/10.4172/23320796.1000271

[13] Media, A., Hamid Reza, N. (2013). A hospital healthcare monitoring system using wireless sensor networks. Journal of Health \& Medical Informatics, 4(2): 1. https://doi.org/10.4172/2157-7420.1000121

[14] Bamisaye, A.J., Adeoye, O.S. (2016). Design of a mobile phone controlled door: A microcontroller based approach. Electrical \& Electronic Systems, 5(1): 1-4. https://doi.org/10.4172/2332-0796.1000167

[15] What is the difference between $2 \mathrm{G}$ and $3 \mathrm{G}$ ? https://www.hutch.lk/difference-2g-3g/, accessed on Feb. 18, 2019. 